\title{
Characteristics of retracted editorial articles in the biomedical literature
}

\author{
Bakthavachalam Elango ${ }^{1}$ (D)
}

Received: 8 March 2021 / Accepted: 23 December 2021 / Published online: 4 January 2022

(c) Akadémiai Kiadó, Budapest, Hungary 2022

\begin{abstract}
The main purpose of this short communication is to identify and analyze retracted editorials in the biomedical literature. Twenty-five of the 33 editorials are chosen for further analysis. All of the editorials were published as commentaries and concise reviews between 1998 and 2021. Due to plagiarism and data-related issues, the majority of the editorial articles were retracted. Alarmingly, one-fifth of the editorials were funded by external agencies, with the USA leading the list of retracted editorials. The average time between the publication of the editorials and their retraction is 2.48 years, and two editorials were retracted with the longest durations; both were written by the same author. The conclusion is that, at the very least, editorial articles should be devoid of research/scientific misconduct.
\end{abstract}

Keywords Publication ethics $\cdot$ Retractions $\cdot$ Editorials $\cdot$ Reasons $\cdot$ PubMed $\cdot$ Bibliometrics

\section{Introduction}

An editorial is an article that expresses the opinion of the journal or magazine or newspaper on a specific topic. It is, in general, a type of short document or article written by editorial member(s) or by someone who has been invited by the editor(s). Editorials give thoughts on current events, explain complicated research and point out study strengths, shortcomings, and alternate interpretations (Leslie \& Hemmings Jr, 2020). In particular, medical editorials serve three purposes: serve as an expert introduction to relevant topics within the journal, provide critical commentary on events of interest to the medical community, and provide guidelines to help practitioners identify best practices and other corresponding references in the literature (Giannoni, 2008). A review of a paper published in a journal, a review of an interesting topic, or a review of very recent developments that may be of interest to journal readers are all examples of editorial articles. Karlen et al. (1997), for example, wanted to bring forward the topic "soil quality" for active discussion and debate among the members of the Soil Science Society of America. Similarly, Hart

Bakthavachalam Elango

elangokb@yahoo.com

1 Department of Library and Information Science, Rajagiri College of Social Sciences, Kochi 683104, Kerala, India 
and Dowell (2011) evaluated the work that was based on the natural-resource-based view, which was originally developed by Hart (1995), in an invited editorial.

The Oxford English Dictionary defines retraction as "the action of revoking or rescinding a decision, edict, or other official action, and it can be used to warn readers about erroneous publication in order to avoid citing or using the results (according to Committee on Publication Ethics). An article might be retracted for a variety of reasons, ranging from an accidental error to a deliberate fraud. Furthermore, retraction notices can also be issued for multiple reasons and editorial articles are also being retracted. One editorial article was recently retracted, making it one of the retracted publications in Indian biomedical literature (Elango, 2021). It is the primary motivation behind this study, which aims to investigate the reasons for retraction of editorial articles in the biomedical literature. Because editorials are the most prevalent type of publication in medical journals, with World Psychiatry publishing more than half of all publications as editorials (Elango \& Hartley, 2018). It also adds to the uniqueness of a particular medical journal by allowing editors to put their personal imprints (Peh \& Ng, 2010). Editorials in medical journals are brief pieces that generally reflect the author's thoughts based on the study or review article published in the same issue as well as how the current article compares to other information on the same topic (Stevens et al., 2006).

Examining the retractions has been of growing interest in recent times. Aspura et al. (2018), Bhatt (2021), Campos-Varela et al. (2020), Elango et al. (2019), Moradi et al. (2018), Rubbo et al. (2019), Samuel et al. (2020), Saikia and Thakuria (2019), and Wray and Andersen (2018) are examples of such investigations. These studies are focused on a single country or discipline or journal or author. However, there is not a study on a certain publication type, thus this study fills that void. This study focuses on the volume of editorial articles that have been retracted in the field of biomedicine and the reasons for the retraction. The number of authors and the type of institution they represent, as well as the type of collaboration and the time it takes for an editorial to retract, are also discussed.

\section{Data and methods}

The data was gathered from PubMed with the following keywords: "retracted publication" [Publication Type] AND editorial [Publication Type]. A total of 581,134 editorial articles were published in biomedical journals. Among these, there are 33 records of retracted editorials as on 28th September 2021 and 25 editorials have been taken for further analysis after the screening process (see Fig. 1). All the original editorial articles and the retraction notices have been downloaded for further analysis. From the original editorial articles, the following information has been collected: publication year, number of authors, institution type of first authors, collaboration type and country of authors. From the retraction notices, the following information has been collected: retraction year and reasons for retraction. A recent 2021 edition of Journal Citation Reports has been consulted for information about journal impact factors. Information on the types of editorial articles has been collected from http://retractiondatabase.org/. For the classification of reasons for retraction, the categories along with potential phrases suggested in the previous study by this author (Elango, 2021) have been adopted: (1) Plagiarism-including self-plagiarism (2) Duplicate Publication-redundant publication (3) Fake data-including data fabrication and falsification (4) Fake review process-manipulation in peer-review (5) Others-reasons other than the above four categories (6) Unknown-retraction notices without clear reason. 


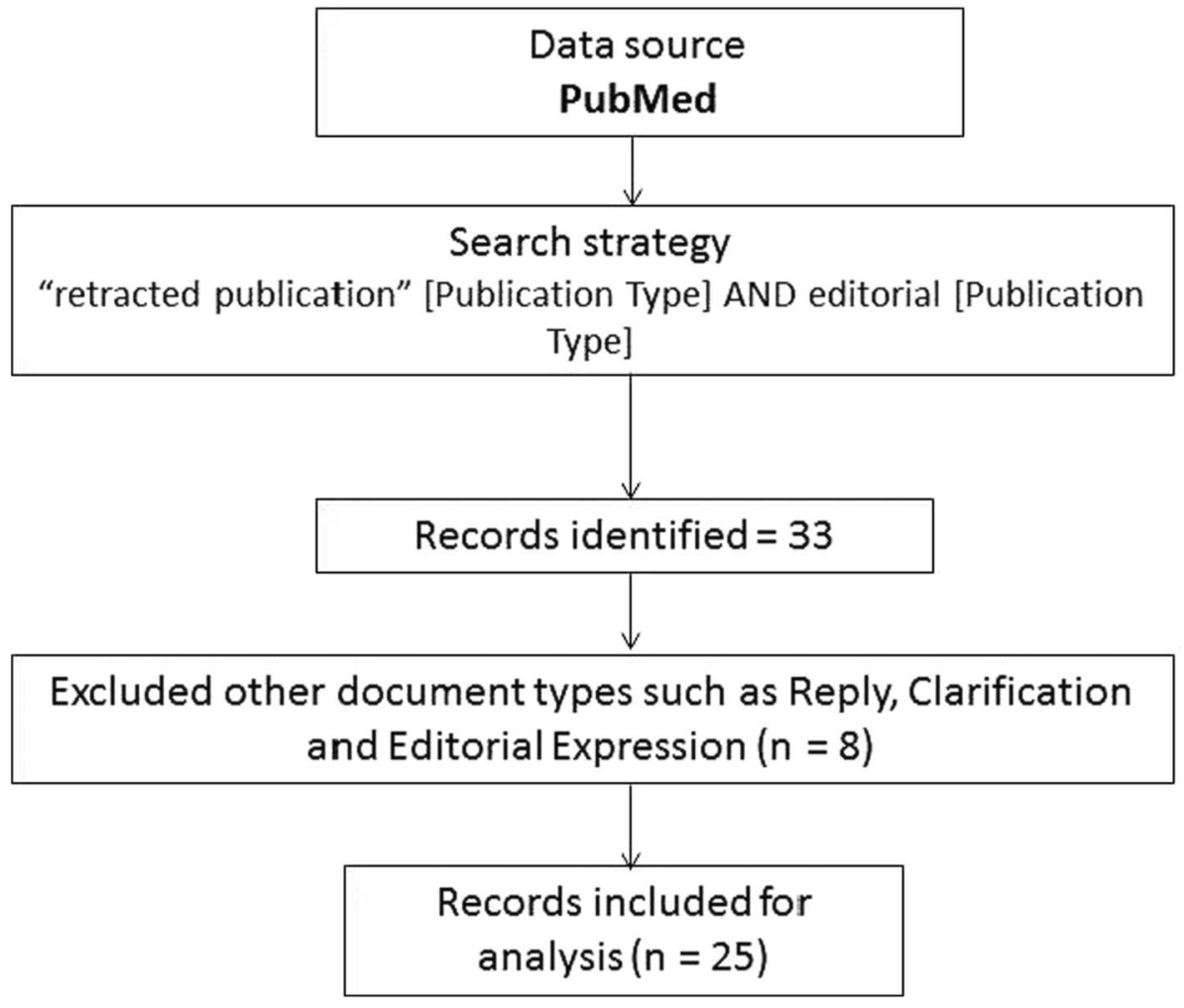

Fig. 1 Search strategy and screening process

\section{Results and discussion}

Among the 33 records on retraction to editorials in PubMed, eight records were excluded since they were published as editorial expression, clarification and reply. Finally, 25 editorial articles are taken for further analysis. Among the 25 editorials, one editorial has been published with the type of "Letter to the Editor" and the retraction information has been found for 22 editorial articles in the retraction watch database http://retraction database.org.

The retracted 25 editorial articles were published in 23 different journals and among these, four had no impact factor. The 2020 impact factor of the 19 journals ranged between 1.711 and 44.544, with an average of 9.10. The top two journals retracting the editorials are Cell Cycle $(n=2)$ and the British Journal of Anaesthesia $(n=2)$. Among these editorials, Boldt had two retracted editorials in the British Journal of Anaesthesia and he is the second top leader in terms of most retractions with 161 (as on 30.12.2021), according to Retraction Watch (https://retractionwatch.com/the-retraction-watch-leaderboard/), and the withdrawal of fraudulent works by Boldt is one of the biggest research scandals in the history of medicine, even though he was regarded as a specialist in intravenous fluid management (Wise, 2013). 
Table 1 Characteristics of retracted editorials

\begin{tabular}{|c|c|c|}
\hline & Frequency & Share of 25 \\
\hline \multicolumn{3}{|l|}{ Publication year } \\
\hline Before 2000 & 1 & 4.00 \\
\hline 2001-2010 & 8 & 32.00 \\
\hline After 2010 & 16 & 64.00 \\
\hline \multicolumn{3}{|l|}{ Type of editorials } \\
\hline Commentary & 19 & 76.00 \\
\hline Concise review & 6 & 24.00 \\
\hline \multicolumn{3}{|l|}{ Number of authors } \\
\hline 1 & 14 & 56.00 \\
\hline 2 & 6 & 24.00 \\
\hline 3 & 2 & 8.00 \\
\hline 4 & 2 & 8.00 \\
\hline 7 & 1 & 4.00 \\
\hline \multicolumn{3}{|l|}{ Collaboration type } \\
\hline Single authored & 14 & 56.00 \\
\hline Intra-institution & 6 & 24.00 \\
\hline Inter-institutions & 2 & 8.00 \\
\hline International collaboration & 3 & 12.00 \\
\hline \multicolumn{3}{|l|}{ Reasons for retraction } \\
\hline Plagiarism & 7 & 28.00 \\
\hline Fake data & 3 & 12.00 \\
\hline Duplicate publication & 3 & 12.00 \\
\hline Fake review process & 1 & 4.00 \\
\hline Others & 6 & 24.00 \\
\hline Unknown & 5 & 20.00 \\
\hline \multicolumn{3}{|l|}{ Institution type of first author } \\
\hline University & 22 & 88.00 \\
\hline Others & 3 & 12.00 \\
\hline
\end{tabular}

In one of the retracted editorial articles, the importance of new-generation mobile technology $(5 \mathrm{G})$ in the establishment of various viruses was highlighted. ${ }^{1}$ External agencies funded five $(20 \%)$ retracted editorials, which discussed aspects of cell programming, ${ }^{2}$ the importance of PIAS1 methylation, ${ }^{3}$ the functional importance of phosphorylation of the

\footnotetext{
${ }^{1}$ Fioranelli, M., Sepehri, A., Roccia, M. G., Jafferany, M., Olisova, O. Y., Lomonosov, K. M., \& Lotti, T. (2020). 5G Technology and induction of coronavirus in skin cells. Journal of Biological Regulators \& Homeostatic Agents, 34 (4), https://doi.org/10.23812/20-269-E-4.

${ }^{2}$ Leri, A., \& Kajstura, J. (2012). Created equal? The many facets of cell reprogramming. Circulation Research, 111, 152-155.

${ }^{3}$ Weber, S., \& Bauer, U. M. (2009). Arginine methylation in interferon signaling: new light on an old story. Cell Cycle, 8 (10), 1464-1465.
} 


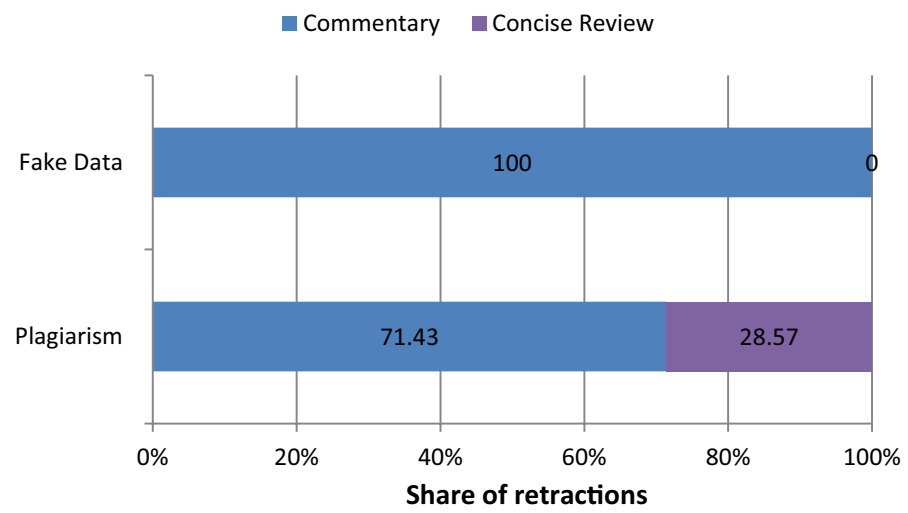

Fig. 2 Editorial type vs. Misconduct

p52/p100 subunit, ${ }^{4}$ the potential of epigenetics ${ }^{5}$ and misconceptions about volume therapy strategies. ${ }^{6}$

Table 1 summarizes the general characteristics of retracted editorials. Between 1998 and 2021, retracted editorials were published: nearly two-thirds were written after 2010, and only one was published before 2000. This finding is in line with the findings of a previous study (Elango, 2021). A little bit more than three-fourths of the editorials were published as commentaries and the remaining were concise reviews. The number of authors on the retracted editorials ranged from one to seven. About $56 \%$ of retracted editorials were authored by single authors, while the remaining $44 \%$ were written with co-authors. In general, single authors were responsible for about $5 \%$ of retracted biomedical literature (Campos-Varela \& Ruano-Ravia, 2019; Elango, 2021). In terms of collaboration, 12\% of retracted editorials had international co-authors, and a similar pattern has been found in Indian biomedical literature (Elango, 2021). Editorial articles were retracted for six different categories of reasons, with plagiarism, duplicate publication, and fake data accounting for more than half of the retractions. Among these three reasons, plagiarism and fake data accounted for $40 \%$ of retractions, indicating the existence of research misconduct (according to the US Office of Research Integrity). An editorial in particular was retracted due to a fraudulent review process, which indicates that malpractice exists in the peer-review process among the editorials as well. There were no explanations for five retractions. Most of the retracted editorials were written by university-affiliated authors.

According to the US Office of Research Integrity, plagiarism and false data are the two types of research/scientific misconduct that can lead to retraction. Figure 2 shows that data fabrication and plagiarism are both common in the commentary, indicating that there is also misconduct among the editorials.

\footnotetext{
${ }^{4}$ Barré, B., \& Perkins, N. D. (2010). Phosphorylation of the p52 NF-кB subunit. Cell Cycle, 9 (24), 4774 4775 .

${ }^{5}$ Uher, R., \& Weaver, I. C. (2014). Epigenetic traces of childhood maltreatment in peripheral blood: a new strategy to explore gene-environment interactions. The British Journal of Psychiatry, 204(1), 3-5.

${ }^{6}$ Boldt, J. (2009). Seven misconceptions regarding volume therapy strategies - and their correction. British Journal of Anaesthesia, 103 (2), 147-151.
} 
Table 2 Countries of contributing authors to retracted editorials

\begin{tabular}{lll}
\hline Country of authors & Frequency & Share of 25 \\
\hline USA & 9 & 36.00 \\
France & 3 & 12.00 \\
Germany & 3 & 12.00 \\
Canada & 3 & 12.00 \\
Italy & 2 & 8.00 \\
UK & 2 & 8.00 \\
Sweden & 1 & 4.00 \\
Brazil & 1 & 4.00 \\
Pakistan & 1 & 4.00 \\
Lebanon & 1 & 4.00 \\
India & 1 & 4.00 \\
Greece & 1 & 4.00 \\
Russia & 1 & 4.00 \\
\hline
\end{tabular}

Since three editorials have authors from multiple countries, total exceeds the number of editorials $(n=25)$

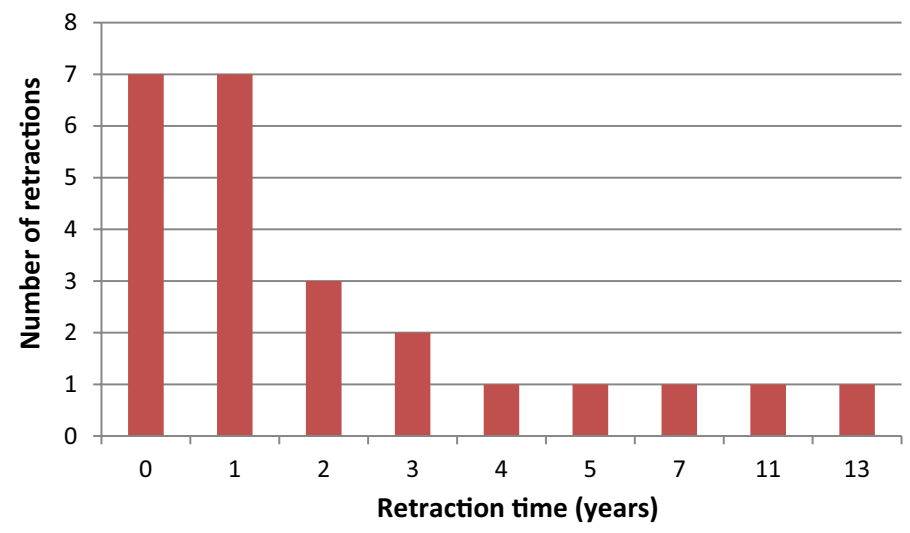

Fig. 3 Retraction time vs. number of retractions

Table 2 shows the countries of authors who contributed to the retracted editorials. With $36 \%$, the USA leads the countries, followed by France (12\%), Germany (12\%), and Canada (12\%). Not surprisingly, the USA was not only the highest ranking country in the world in terms of the number of retractions in the field of life sciences (Bhatt, 2021), but also the top-ranked country in terms of producing high-quality research output (Nature Index, 2021). The top six countries are all members of the G7 group, which has a stronghold in a variety of research areas (Elango et al., 2013).

The majority of editorials were retracted in the same year they were published or in the next year (Fig. 3). The average retraction time (from publication to retraction) is 2.48 years, which is short in comparison to previous studies; 2.86 years for Indian biomedical literature (Elango, 2021) and 3.8 years for life-sciences literature (Bhatt, 2021). Two editorials have been retracted with the longest durations of 11 and 13 years respectively; both were written by the same author and were retracted for citing fraudulent 
works. The British Journal of Anaesthesia retracted both editorials after an average of 12 years.

In general, editorial articles in the field of medicine are written by editorial board members of the concerned journal. Examples of such journals are the Lancet and BMC Medicine. It is to be noted that these journals did not have retracted editorial articles.

Despite the fact that the number of retracted editorials is very low, it is a concerning element. Because retraction of editorial articles tarnishes the editorial systems' credibility and it is the sole responsibility of the editor(s) to detect and retract erroneous articles from their journals.

This study has the following limitations: (i) There has been no investigation into the sources of the retraction. (ii) The authorship (in-house editor or invited) of editorials has not been investigated. (iii) The gender of the authors has not been investigated. (iv) In this study, only editorials indexed in the PubMed database have been considered; the results may differ if other databases are used.

\section{Concluding remarks}

This short study examines the retracted editorials in the field of biomedicine. The retracted editorials were published in 23 different journals and two journals published two editorials each. After 2010, the majority of the retracted editorial articles were published. External agencies provide funding for one-fifth of the editorials and more than $50 \%$ were retracted due to plagiarism, fake data and duplication.

Since retracted publications are wasting scientific resources in the form of editors, publishers and reviewers, at the very least, editorial articles should be free from any kind of scientific and/or research misconduct such as plagiarism or data fabrication.

Funding Not applicable.

\section{Declarations}

Conflict of interest The author declares that he has no conflict of interest.

\section{References}

Aspura, M. Y. I., Noorhidawati, A., \& Abrizah, A. (2018). An analysis of Malaysian retracted papers: Misconduct or mistakes? Scientometrics, 115(3), 1315-1328.

Bhatt, B. (2021). A multi-perspective analysis of retractions in life sciences. Scientometrics, 126(5), 4039-4054.

Campos-Varela, I., \& Ruano-Raviña, A. (2019). Misconduct as the main cause for retraction. A descriptive study of retracted publications and their authors. Gaceta Sanitaria, 33, 356-360.

Campos-Varela, I., Villaverde-Castañeda, R., \& Ruano-Raviña, A. (2020). Retraction of publications: A study of biomedical journals retracting publications based on impact factor and journal category. Gaceta Sanitaria, 34(5), 430-434.

Elango, B. (2021). Retracted articles in the biomedical literature from Indian authors. Scientometrics. https://doi.org/10.1007/s11192-021-03895-1.

Elango, B., \& Hartley, J. (2018). Publication trends in a high impact journal: The case of World Psychiatry. Library Hi Tech News, 35(1), 25-30. 
Elango, B., Kozak, M., \& Rajendran, P. (2019). Analysis of retractions in Indian science. Scientometrics, 119(2), 1081-1094.

Elango, B., Rajendran, P., \& Bornmann, L. (2013). Global nanotribology research output (1996-2010): A scientometric analysis. PLoS ONE, 8(12), e81094.

Giannoni, D. S. (2008). Medical writing at the periphery: The case of Italian journal editorials. Journal of English for Academic Purposes, 7(2), 97-107.

Hart, S. L. (1995). A natural-resource-based view of the firm. Academy of Management Review, 20(4), 986-1014.

Hart, S. L., \& Dowell, G. (2011). Invited editorial: A natural-resource-based view of the firm: Fifteen years after. Journal of Management, 37(5), 1464-1479.

Karlen, D. L., Mausbach, M. J., Doran, J. W., Cline, R. G., Harris, R. F., \& Schuman, G. E. (1997). Soil quality: A concept, definition, and framework for evaluation (a guest editorial). Soil Science Society of America Journal, 61(1), 4-10.

Leslie, K., \& Hemmings, H. C., Jr. (2020). Excellence in editorials: Fulfilling their critical role in the medical literature. British Journal of Anaesthesia, 125(5), 639-641.

Moradi, S., \& Janavi, E. (2018). A scientometrics study of Iranian retracted papers. Iranian Journal of Information Processing and Management, 33(4), 1805-1824.

Nature Index (2020). The ten leading countries in natural-sciences research. Retrieved 23 August, 2021, from https://doi.org/10.1038/d41586-020-01231-w.

Peh, W. C., \& Ng, K. H. (2010). Writing an editorial. Singapore Medical Journal, 51(8), 612-615.

Rubbo, P., Helmann, C. L., Bilynkievycz dos Santos, C., \& Pilatti, L. A. (2019). Retractions in the engineering field: A study on the web of science database. Ethics \& Behavior, 29(2), 141-155.

Saikia, P., \& Thakuria, B. (2019). Retraction of papers authored by Yuhji Saitoh-Beyond the Fujii phenomenon. Indian Journal of Anaesthesia, 63(7), 571-584.

Samuel, S., Cherian, J. M., \& Thomas, A. M. (2020). Comprehensive analysis of retracted publications in dentistry: A 23-year review. International Journal of Dentistry. https://doi.org/10.1155/2020/8881352.

Stevens, L. M., Lynm, C., \& Glass, R. M. (2006). Medical journals. JAMA, 295(15), 1860-1860.

Wise, J. (2013). Boldt: The great pretender. BMJ, 2013, 346.

Wray, K. B., \& Andersen, L. E. (2018). Retractions in science. Scientometrics, 117(3), 2009-2019. 